irritative eczema, with exfoliated epidermis, and a profuse sero-purulent discharge. When the sore was cleaned it had a smooth, glazed, pink surface; quite level with the surround ing skin, very sharply detined, scarcely a trace of inflammatory redness extending beyond its edge. It was painless and almost insensitive. There were no granulations, as apparently only the cuticular layer was lost, having a surface exactly like that seen when the cuticle is rubbed off a dissecting room subject, except that it was a bright pink colour.

Almost everything that could be thought of, in the shape of lotions, creams, powders, was used to try to check the copious serous discharge and get it to heal, but they were absolutely of no avail, being literally washed or floated off by the discharge. However, in about ten days the exudation began to lessen the epithelium began to grow in from the edge, exactly as in a burn, and it was soon seen to be creeping up from the bottom of the umbilical recess. I at once commenced skin grafting, but though from from six to ten grafts were put on almost every day, comparatively few " took;" whether this was due to the constant motion of the part from respiration or not I cannot say. None lived in the central part. Healing steadily progressed till the last week of July, when the sore was reduced to an irregular patch about 3 by $3 \frac{1}{2}$ inches, lying just above the umbilicus. After the healing process commenced it, for the first time, became painful, and was very sensitive to various applications. Boric lotion caused considerable burning, and even a very weak ointment of salicylic acid could not be borne at all. When healing ceased it remained very irritable, the surface became grey and gradually covered with a thick semi-translucent material that could not be washed off, and which almost exactly resembled boiled white fish skin. On August gth the whole sore was deeply cauterised with solid nitrate of silver, some days after a thick slough separated, but the surface underneath was grey and showed no sign of granulations. It gradually became covered with a thick false membrane, not like the previous one but tough, yellow, and opaque, and there was no tendency to heal. On September and the patient was again put under ether, and the sore was scraped till a bleeding surface was obtained, and then the actual cautery applied freely to the whole. Since this operation no slough has separated, the charred surface came away in particles, leaving a thick leathery insensitive false membrane underneath. In this state it is at present, sixteen weeks after exposure to the $x$ rays.

From the position of the sore the patient's condition was uncomfortable in the extreme. Most of the time he had to remain in bed with a cradle over the abdomen, otherwise no dressings or applications could be used. During the treatment he had a severe renal attack, which necessitated the use of morphine. All these conditions, with the actual pain suffered, the mental worry and anxiety, brought about a condition of general debility, which is, I believe, answerable for the non-healing of the sore, rather than any inherent peculiarity in itself. The patient has lately so much improved in general health that the sore already presents a better appearance, and it will doubtless soon yield to treatment and close in like any ordinary ulcer. I think it right, however, to report the case without any further delay, though incomplete. The only similar case that I have heard of is that reported in the Eрiтомe, British Medical Journal, August 15 th, 1896.

\section{A CASE OF CONGENITAL WORD BLINDNESS}

\section{By W. PRINGLE MORGAN, M.B.,} Seaford, Sussex.

Percy F.-a well-grown lad, aged I4-is the eldest son of intelligent parents, the second child of a family of seven. He has always been a bright and intelligent boy, quick at games, and in no way inferior to others of his age.

His great difficulty has been-and is now-his inability to learn to read. This inability is so remarkable, and so pronounced, that I have no doubt it is due to some congenital defect.

He has been at school or under tutors since hewas 7 years old, and the greatest efforts have been made to teach him to read, bitt, in spite of this laborious and persistent training, he can only- with difficulty spell out words of one syllable.
The following is the result of an examination $I$ made a short time since. He knows all his letters, and can write them and read them. In writing from dictation he comes to grief over any but the simplest words. For instance, I dictated the following sentence: "Now, you watch me while I spin it." He wrote: "Now you word me wale I spin it"; and, again, "Carefully winding the string round the peg" was written: "Calfuly winder the sturng rond the Pag."

In writing his own name he made a mistake, putting "Precy" for "Percy," and he did not notice the mistake until his attention was called to it more than once. I asked him to write the following words :-

$$
\begin{aligned}
& \text { Subject } \\
& \text { Without } \\
& \text { Without } \\
& \text { Shilling } \\
& \begin{array}{lll}
\ldots & \ldots & ", \\
\ldots . & \ldots & ", \\
\ldots & \ldots &
\end{array} \\
& \begin{array}{ccr}
\ldots & \ldots & \text { scone } \\
\ldots & \ldots & \text { scojock } \\
\ldots & \ldots & \text { wichout } \\
\ldots & \ldots & \text { Englis } \\
\ldots & \ldots & \text { sening } \\
\ldots & \ldots & \text { seasow }
\end{array}
\end{aligned}
$$

He was quite unable to spell the name of his father's house, though he must have seen it and spelt it scores of times. In asking him to read the sentences he had just written a short time previously he could not do so, but made mistakes over every word except the very simplest. Words such as "and" and "the" he always recognises.

I then asked him to read me a sentence out of an easy child's book without spelling the words. The result was curious. $\mathrm{He}$ did not read a single word correctly, with the exception of " and," " the," " of," "that," etc.; the other words seemed to be quite unknown to him, and he could not even make an attempt to pronounce them.

I next tried his ability to read figures, and found he could do so easily. He read off quickly the following : $785,852,017$, 20,969 , and worked out correctly: $-(\alpha+x)(a-x)=a^{2}-x^{2}$ He could not do the simple calculation $4 \times \frac{1}{2}$, but he multiplied 749 by 867 quickly and correctly. He says he is fond of arithmetic, and finds no difficulty with it, but that printed or written words " have no meaning to him" and my examination of him quite convinces me that he is correct in that opinion. Words written or printed seem to convey no impression to his mind, and it is only after laboriously spelling them that he is able, by the sounds of the letters, to discover their import. His memory for written or printed words is "o defective that he can only recognise such simple ones as "and," "the," "of," etc. Other words he never seems to remember, no matter how frequently he may have met them.

He seems to have no power of preserving and storing up the visual impression produced by words-hence the words though seen, have no significance for him. His visual memory for words is defective or absent; which is equivalent to saying that he is what Kussmaul has termed "word blind" (cacitas syllabaris et verhalis).

Cases of word blindness are always interesting, and this case is, I think, particularly so. It is unique, so far as I know, in that it follows upon no injury or illness, but is evidently congenital, and due most probably to defective development of that region of the brain, disease of which in adults produces practically the same symptoms-that is, the left angular gyrus.

I may add that the boy is bright and of average intelligence in conversation. His eyes are normal, there is no hemianopsia, and his eyesight is good. The schoolmaster who has taught him for some years says that he would be the smartest lad in the school if the instruction were entirely oral. It will be interesting to see what effect further training will have on his condition.

His father informs me that the greatest difficulty was found in teaching the boy his letters, and they thought he never would learn them. No doubt he was originally letter blind (cacitas litteralis), but by dint of constant application this defect has been overcome.

Belgian Climatological Congress.-A Congress of Medical Climatology and Hydrology to be held at Brussels in connection with the Exhibition of 1897 is being organised under the auspices of the Belgian Royal Society of State Medicine. The object is to make known the places in Belgium, with the special addvantages presented by each in point of climate, etc., which would be suitable for the establishment of sanatoria. 